\title{
Modernidade e contemporaneidade nas poéticas do Brasil e de Moçambique: do "Sentimento do Mundo" de Carlos Drummond de Andrade à metapoesia "Metamorfose" de Luís Patraquim
}

Modernity and contemporaneity in poetic of Brazil and Mozambique: the "Feeling of the World" by Carlos Drummond de Andrade to the metapoetry "Metamorphosis" of Luis Patraquim

Thiago Lauriti

Mestre em Letras com ênfase em Literatura Infantil/Juvenil e Literatura Comparada pela Faculdade de Filosofia, Letras e Ciências Humanas da Universidade de São Paulo (FFLCH/USP); Professor de graduação e pósgraduação nas áreas de Pedagogia e Letras da Universidade Nove de Julho

(UNINOVE).

São Paulo, SP - Brasil. thiagolauriti@uninove.br

\section{Resumo}

No presente artigo, pretende-se constituir um estudo comparativo dos poemas "Sentimento do mundo", de Carlos Drummond de Andrade, e "Metamorfose", de Luis Carlos Patraquim, com o objetivo de identificar as marcas do pós-modernismo literário que caracterizam a metapoesia, utilizando como ferramental analítico Hassan (1971), Connor (1996) e Leite (1998), que se mostraram muito produtivos para a verificação dos indícios de modernidade e contemporaneidade presentes nas poesias selecionadas.

Palavras-chave: Comparativismo. Metapoesia. Pós-modernismo.

Abstract

In this article it is intended to establish a comparative study of the poems "Feeling the world" by Carlos Drummond de Andrade and "Metamorphosis" by Luis Carlos Patraquim in order to identify the marks of postmodernism literary that characterize metapoetry, using Hassan's (1971), Connor's (1996) as well as Leite's (1998) analytical tools and which proved very productive for verification of the evidence of modernity and contemporaneity present in selected poems.

Key words: To draw comparison. Metapoetry. Postmodernism. 
"A história é um palimpsesto e a cultura é permeável ao tempo passado, presente e futuro."

(HASSAN, 1996)

\section{Introdução}

Neste artigo, não se pretende construir uma exaustiva análise dos poemas "Sentimento do mundo", de Carlos Drummond de Andrade, e "Metamorfose", de Luis Carlos Patraquim; trata-se, isto sim, de realizar uma análise comparativa entre ambos, com o objetivo de identificar as marcas do pós-modernismo literário que caracterizam a metapoesia de Patraquim. Para tal intento, apoiamo-nos na obra de Connor (1996), Cultura pós-moderna: introdução às teorias do contemporâneo, e no artigo de Hassan, Dismemberment of Orpheus: Towards a Postmodern Literature, incluído na obra citada. Em tais textos, os autores oferecem um quadro representativo que ilustra, de maneira clara, as oposições entre o modernismo e o pós-modernismo, configurando um modelo teórico importante e produtivo para a compreensão das marcas das poéticas contemporâneas. Valemo-nos, também, como referencial teórico, do trabalho de Ana Mafalda Leite (1998) sobre a trajetória de Luís Carlos Patraquim, o intérprete de um legado.

A perspectiva comparativa se justifica na medida em que a própria Ana Mafalda Leite defende que a poética de Patraquim é uma "poética de correspondências" que confisca intertextualmente imagens, estilos, temas que repõe e expõe nas suas formulações, reivindicando, desse modo, um direito de herança que remonta a Camões, Maiakovski, Lorca, Blake, Eliot, Drummond, entre outros.

\section{Diálogos transoceânicos entre Drummond e Patraquim}

Luís Calos Patraquim, autor de Monção, assume nessa obra de 1989 o exercício da metapoesia, fazendo um jogo onírico com a linguagem. A cadência singular de seus versos, aliada ao permanente jogo intertextual, possibilita o surgimento de uma palavra poética que dialoga com vozes significativas da literatura e da arte. Particularmente no poema "Metamorfose", o poeta cria um texto que é gerador de cumplicidades e oposições, levando o leitor a reconhecer e 
a participar de seu canto polifônico repleto de traços da pós-modernidade literária que transcendem o tempo lírico em direção à universalidade. Assim, Patraquim, por sua invenção poética, dialoga com seus compatriotas e com outros poetas de além-mar como Carlos Drummond de Andrade, formando com eles um coro marcado pelo sentimento de mundo cujo tom é marcado pelo diapasão da dor. Nesse sentido, a flexibilidade rítmica que imprime uma cadência singular aos versos de "Metamorfose" talvez seja resultante da conscientização, da percepção dessas dores que impulsionam a vida do homem e ultrapassam as fronteiras geográficas e da memória.

Rita de Cássia Natal Chaves, em sua obra Angola e Moçambique: experiência colonial e territórios literários, publicada em 2005, vê a contemporaneidade literária africana definida por um misto de "fragmentação e ruptura", características resultantes das mudanças processadas nas sociedades que buscam uma nova ordem social, política e econômica. Nessa perspectiva, o retorno à tradição, o movimento dialógico com outras artes, com poetas locais e de outras nacionalidades, "[...] impõe-se ao escritor que não se quer cúmplice da destruição [...]", mas inventor de uma nova poética capaz de encontrar novos caminhos para evitar o caos, "[. . .] quando consegue assegurar à palavra o direito e o poder de continuar fundando utopias [...]". (CHAVES, 2005, p. 63)

Nesse contexto, alguns princípios de Hassan (apud CONNOR, 1996) para marcar a contemporaneidade literária já podem ser delineados. São eles: o intertexto, a desconstrução, a dispersão, a ironia, a ausência, a antiforma (disjuntiva, aberta), a espontaneidade e a exaustão/silêncio, entre outros.

Sentimento do mundo

\author{
Tenho apenas duas mãos \\ e o sentimento do mundo, \\ mas estou cheio de escravos, \\ minhas lembranças escorrem \\ e o corpo transige \\ na confluência do amor. \\ Quando me levantar, o céu \\ estará morto e saqueado, \\ eu mesmo estarei morto, \\ morto meu desejo, morto
}


o pântano sem acordes.

Os camaradas não disseram

que havia uma guerra

e era necessário

trazer fogo e alimento.

Sinto-me disperso,

anterior a fronteiras,

humildemente vos peço

que me perdoeis.

Quando os corpos passarem,

eu ficarei sozinho

desafiando a recordação

do sineiro, da viúva e do microscopista

que habitavam a barraca

e não foram encontrados

ao amanhecer

esse amanhecer

mais que a noite.

(Carlos Drummond de Andrade)

Os poemas da obra "Sentimento do mundo" foram produzidos de 1935 a 1940. São 28 no total e o primeiro, que deu nome ao livro, revela uma amarga visão de mundo. Insere-se na segunda fase modernista que é caracterizada, sobretudo, pelos seguintes constructos: mistura de estilos, em que se combinam o elevado e o banal, e os temas sérios e problemáticos são tratados com linguagem vulgar; percepção existencial, com pretensões universalistas; envolvimento com a problemática social, presente na atitude de denúncia e revolta diante das injustiças; e metapoesia, isto é, reflexão da poesia sobre a própria poesia, demonstrando a autoconsciência do poeta em relação ao seu próprio trabalho com as palavras.

Quando "Sentimento do mundo" foi escrito, experimentava-se a recuperação da Primeira Guerra Mundial, mas já era iminente um segundo conflito de tal tipo com o crescimento do nazi-fascismo e a imposição, no Brasil, do Estado Novo de Getúlio Vargas. Esse cenário transparece no poema, pois Drummond lança-se ao encontro da história e da experiência coletiva, solidarizando-se social e politicamente, descobrindo na luta a forma de apreender a vida como um todo. No poema 
sob análise, a dor é o "sentimento do mundo", é a dor de todos os homens que se concentra em um só, no "eu poético": "Quando os corpos passarem, eu ficarei sozinho desafiando a recordação do sineiro, da viúva e do microscopista [. . .]."

O poeta inicia indicando suas limitações para ver o mundo, "Tenho apenas duas mãos", mas aponta, em seguida, elementos auxiliares que o ajudarão a suprir suas deficiências de visão: escravos, lembranças e o mistério do amor (versos 3 a 5). O pessimismo é anunciado pela morte do céu e do próprio poeta: "Quando me levantar, o céu estará morto e saqueado, eu mesmo estarei morto, morto meu desejo, morto o pântano sem acordes". Apesar da ajuda dos "camaradas", vale dizer, dos companheiros de trajetória da vida, o eu-poético disperso e retorcido não consegue entender e decifrar os códigos existenciais e por isso humildemente se desculpa. Nos versos finais, um futuro muito negativo é descortinado: mortos, lembranças, pessoas que "não foram encontradas" e que sumiram nas batalhas da vida, concluindo que o futuro ("o amanhecer") é mais negro que a noite.

Trata-se de um canto que oscila entre o pessoal e o coletivo, que ecoa e sensibiliza - o sofrimento do ser humano, a guerra e a solidão predominam neste poema. A dor se faz presente e o eu-lírico se resguarda e canta o outro, tão mais importante que ele próprio. Dada a realidade da guerra, o homem desesperançado da humanidade mostra sua insubmissão diante desse cenário. O "Sentimento de mundo", em Drummond, aparece envolto em um cenário poético marcado pela desconstrução do sujeito poético, pela exaustão que silencia a voz poética, pelo sentimento de ausência, pela ironia e pela indeterminação.

Esta digressão teve por objetivo tornar mais claro para o leitor o contexto da influência de Drummond em "Metamorfose”, de Luís Carlos Patraquim, que será analisado a seguir.

\title{
Análise da metapoesia em Patraquim e Drummond
}

\author{
Metamorfose \\ (Ao poeta José Craveirinha) \\ [... . quando o medo puxava lustro à cidade \\ eu era pequeno
}

vê lá que nem casaco tinha 
nem sentimento do mundo grave

ou lido Carlos Drummond de Andrade

os jacarandás explodiam na alegria secreta de serem vagens

e flores vermelhas

e nem lustro de cera havia

para que o soubesse

na madeira da infância

sobre a casa

a Mãe não era ainda mulher

e depois ficou Mãe

e a mulher é que é a vagem e a terra

então percebi a cor

e metáfora

mas agora morto Adamastor

tu viste-lhe o escorbuto e cantaste a madrugada

das mambas cuspideiras nos trilhos do mato

falemos dos casacos e do medo

tamborilando o som e a fala sobre as planícies verdes

e as espigas de bronze

as rótulas já não tremulam não e a sete de Março

chama-se Junho desde um dia de há muito com meia dúzia

de satanhocos moçambicanos todos poetas gizando

a natureza e o chão no parnaso das balas

falemos da madrugada e ao entardecer

porque a monção chegou

e o último insone povoa a noite de pensamentos grávidos

num silêncio de rãs a tisana do desejo

enquanto os tocadores de viola

com que latas de rícino e amendoim

percutem outros tendões da memória

e concreta

a música é o brinquedo

a roda

e o sonho

das crianças que olham os casacos e riem 
na despudorada inocência deste clarão matinal

que tu

clandestinamente plantaste

AOS GRITOS

(Luís Carlos Patraquim)

O poema faz parte do livro Monção, publicado em 1980, e evidencia a substituição da "poesia da utopia, do epos revolucionário" (BOSI, 1983, p.187) pela poesia dos afetos, do lirismo subjetivo. Patraquim inaugura na cena literária de Moçambique uma poesia de matiz existencial, preocupada não só com as emoções interiores, mas com as origens, com as paisagens do presente e do passado e com o próprio fazer poético. Colocando-se contra as ideias articuladas pelo epos revolucionário, Patraquim opta pela poética subjetiva, dialogando com representantes do antigo lirismo moçambicano.

No poema "Metamorfose", observa-se, conforme já assinalaram vários estudiosos da poesia de Patraquim, um visível movimento de intertextualidade com conhecidos versos de José Craveirinha, a quem dedica explicitamente o poema, e com o "Sentimento do mundo", de Drummond, conforme o trecho a seguir:

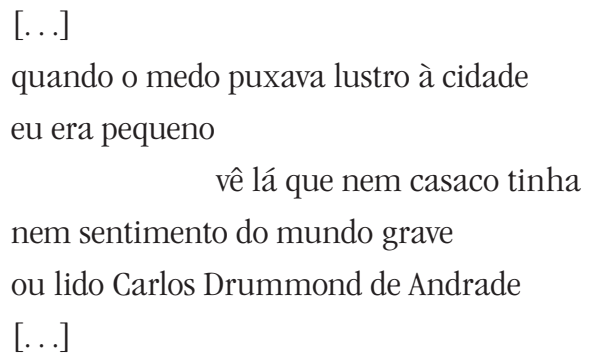

Embora fale da "monção" e "da morte do Adamastor", que são metáforas da independência e do fim dos tempos coloniais, o poema, dialogando com os versos de Craveirinha e Drummond, procura exorcizar o medo que há séculos havia se instalado em Moçambique.

O eu-poético mostra consciência dos prejuízos físicos e emocionais que grande parte do povo moçambicano sofreu, sendo necessário agora restaurar emoções individuais como o amor, o desejo, os sonhos e a imaginação que ficaram durante anos censurados pela longa e arbitrária dominação que sofreram. 
O título já constitui um importante elemento de orientação de leitura: a metamorfose, pois busca marcar uma transformação da forma no tempo, podendo referir-se tanto à mudança da poesia quanto à mudança da nação. Desse modo, justifica-se considerá-lo como um metapoema, já que se está falando do próprio fazer poético. Essa orientação de leitura pede um leitor atento, capaz de redescobrir as "metonímias" presentes no poema, considerando essas direções ao observar, por exemplo, o jogo de palavras que é feito nos versos:

[...]

a Mãe não era ainda mulher

e depois ficou Mãe

e a mulher é que é a vagem e a terra

então percebi a cor

e metáfora

$[\ldots]$

Observa-se que o binômio "mãe-mulher" pode referir-se à nação africana, à mater-palavra que dá origem ao poema e também à mãe rememorada por um sujeito-lírico. É a fluidez dessa "desconstrução" de sentidos, marcada pela "dispersão", uma outra característica que marca a contemporaneidade de Patraquim. O estilo do poeta em "Metamorfose" é estilhaçado por versos soltos, estrofes que variam, sem preocupação com a rima e com a flexibilidade rítmica, o que permite pintar Moçambique com imagens dissonantes que desautomatizam os sentidos habituais da palavra. O onírico se apresenta como caminho de busca da identidade esfacelada, como se observa nos versos abaixo:

[...]

mas agora morto Adamastor

tu viste-lhe o escorbuto e cantaste a madrugada

das mambas cuspideiras nos trilhos do mato

falemos dos casacos e do medo

tamborilando o som e a fala sobre as planícies verdes

e as espigas de bronze

as rótulas já não tremulam não e a sete de Marco

chama-se Junho desde um dia de há muito com meia dúzia 
de satanhocos moçambicanos todos poetas gizando

a natureza e o chão no parnaso das balas

[...]

Nesses versos, o poeta faz referência ao Gigante Adamastor cantado por Camões (Cabo das Tormentas) se desfazendo pela miséria, pela fome e pela guerra (escorbuto), para referir-se à morte do colonizador português na natureza do continente africano, levando, assim, o poeta a cantar "a madrugada", isto é, o tempo de um lugar futuro, o dia que está por vir, o tempo-espaço cronotópico de que nos fala Bakhtin (1992), que cria um vínculo substancial a ligar os tempos e os espaços presente, passado e futuro. Tudo no universo espaço-temporal de "Metamorfose" é cronotópico, já que sob os olhos de Patraquim os cenários e tempos se impregnam de um tempo histórico criador que determina a percepção do poeta, tecendo na rede textual as múltiplas facetas da história de seu país. Sua "poiesis carnívora”, como a denomina Secco (2006, p. 146), está "prenhe de metáforas insólitas que deixam sangrar a memória”.

Concretiza-se o que Leite (2003, p. 127) aponta no poeta como uma “[. . .] textualidade onde se revela e, ao mesmo tempo, se rasura a dimensão de natureza ideológica, que se inscreve, todavia, obtusa e transversalmente [...]". Defende a autora o que se comprova no poema, isto é, que Patraquim se faz "[...] coletor de sinais, de versos, títulos, estilos, tendências, cuja herança conflui nos seus poemas em estreitas correspondências [...]". Ele atualiza no seu texto a "[...] leitura hibridizada do seu passado [...]", confiscando imagens, estilos, temas, desvelando uma arqueologia cultural que o coloca como "[...] intérprete desse legado [...]" e na qual se podem "ler" seus precursores. A autora ainda chama a atenção para o que considera a marca do poeta: a estrutura alegórica que permite que o leitor perceba que seu texto tem sempre uma leitura espelhada, por mais fragmentada que possa ser.

Importante ressaltar que esse traço de Patraquim é entendido pela autora como a busca de um lugar de reconhecimento, "de abrigo identitário": mirandose em múltiplos espelhos desfocados, o poeta cria uma "teia palimpséstica" em que sua obra poética assume uma forma pessoal e passa a ser reconhecida. Ela também registra que o próprio hábito da "dedicatória” em seus poemas e a carga afetiva que denota têm a função de rememorar e aditar um percurso poético 
anterior, indicando no texto um legado escolhido como tradição e lhes conferindo um acréscimo de sentido.

Constatamos assim, por esta breve análise do poema "Metamorfose", as marcas que instauram em Luís Carlos Patraquim a procura de um itinerário poético próprio, que apesar de se alicerçar em propostas anteriores, no retorno à tradição e ao diálogo com outras nacionalidades, não o torna cúmplice de destruição do sentido, mas inventor de uma poética que assegura a ele o poder de continuar fundando diferentes utopias.

\section{Considerações finais}

Após essa breve incursão comparativa que partiu do poema "Sentimento do mundo" de Drummond e aportou em "Metamorfose" de Patraquim, identificamos a presença de alguns princípios que marcam a contemporaneidade literária como apresentados por Hassan (1996). Em "Metamorfose", por exemplo, percebe-se a decomposição de princípios centrais da literatura como o da "autoria", já que o poeta incorpora em seu canto polifônico outras vozes poéticas e artísticas, em um ritmo gerador tanto de cumplicidades quanto de oposição, provocando uma "dispersão" do eu-poético. Essa opção pelo "intertexto" desintegra e desconstrói a matéria poética, delineando-a como um mosaico em que diferentes vozes podem caber. O objeto poético, antes visto como obra acabada, passa a ser exercitado como um "processo".

A expressão marcadamente "metonímica" também é outra característica da pós-modernidade literária encontrada em Patraquim, na qual o regionalismo insular representa o tempo-espaço mítico e cronotópico de fundação da nação enquanto representação de um tempo-espaço de cruzamentos culturais de origens diversas, daí as referências polifônicas recorrentes no poema. É o que leva Leite (2003, p. 137) a considerar a literatura moçambicana como um "[...] palimpsesto arquitetônico, geográfico, literário, de textualidade cultural [...] permitindo a criação de um mito cultural unificador, devido à sua multiplicidade de registros [...]”. Descentralizam-se as estratégias discursivas e o diálogo que Patraquim estabelece com Drummond pode ser entendido como uma conversa com os valores do modernismo, representado em sua poética por alguns princípios como o da centração do sujeito poético, da metáfora (em vez da metonímia), da 
seleção (em vez da combinação), da interpretação (em vez da desleitura), do código dominante (em vez do idioleto), da causa (em vez do vestígio), da determinação (em vez da indeterminação).

A textualidade em Patraquim é transcultural, exige quase um processo de tradução e de recriação que faz com que o leitor "ausente", distante do poeta, movimente-se para o espaço do outro em interação dinâmica, para aproximar-se da palavra poética. Assim, sua escrita instaura a distância na tessitura do poema exigindo um trabalho de reconstrução do sentido do texto em uma situação de incomunicabilidade latente, mas que por outro lado permite que o leitor estabeleça uma rede de relações de sentido mais ampla. Já em Drummond observa-se a presença de um leitor previsto no próprio ato de criação, o que dá ao texto uma forma conjuntiva, mais fechada, revelando um projeto estético mais hierarquizado e com propósitos definidos e estratégias discursivas centralizadas em um sujeito poético.

Essa "presença" ("modernidade") / "ausência" ("pós-modernidade") dá origem a outro binômio que ajuda a compreender melhor os poemas analisados: as duas formas de ironia, a "disjuntiva" do modernismo e a "suspensiva" do pós-modernismo (CONNOR, 1996, p. 97). A "ironia disjuntiva" de Drummond funciona como resposta a um mundo percebido como fragmentado, representando o desejo de, num só movimento, ser fiel à incoerência e transcendê-la. Já a "ironia suspensiva" da pós-modernidade que se encontra em Patraquim é vista pelos teóricos como a marca de uma arte nascida dos acessos de fúria modernista, combinando um conhecimento realista da incoerência com uma tolerância benigna em relação a elas e levando a uma indecisão quanto aos significados ou relações das coisas que é compensada pela tendência a conviver com o aleatório, com a incerteza, com o múltiplo e com o absurdo.

\section{Referências}

BAKHTIN, Mikhail. Estética da criação verbal. 1. ed, São Paulo: Martins Fontes, 1992. BOSI, Alfredo. O ser e o tempo da poesia. São Paulo: Cultrix, 1983.

CHAVES, Rita de Cássia Natal. Angola e Moçambique: experiência colonial e territórios literários. 1. ed. Cotia: Ateliê, 2005. 
; SECCO, Carmem Lúcia Tindó R.; MACÊDO, Tânia Celestino (Orgs.). Brasil/ África: como se o mar fosse mentira. São Paulo: Editora UNESP; Luanda: Chá de Caxinde, 2006.

CONNOR, Steve. Cultura pós-moderna: introdução às teorias do contemporâneo. São Paulo: Loyola, 1996.

HASSAN, Ihab. Dismemberment of Orpheus: Towards a Postmodern Literature. New York: Oxford University Press 1971. In: CONNOR, Steve. Cultura pós-moderna: introdução às teorias do contemporâneo. São Paulo: Loyola, 1996.

LEITE, Ana Mafalda. Literaturas africanas e formulações pós-coloniais. Lisboa: Colibri, 2003.

recebido em 14 nov. 2011 / aprovado em 26 jun. 2012

\section{Para referenciar este texto:}

LAURITI, T. Modernidade e contemporaneidade nas poéticas do Brasil e de Moçambique: do "Sentimento do Mundo" de Carlos Drummond de Andrade à metapoesia "Metamorfose" de Luís Patraquim. Dialogia, São Paulo, n. 15, p. 121-132, 2012. 